\title{
De Novo Hepatocellular Carcinoma in Hepatitis C- Related Cirrhosis: Are Advanced Glycation end Products a Key Driver?
}

\author{
Ahmed Abdel-Razik ( $\square$ ahmedabdelrazik76@gmail.com ) \\ Mansoura University Faculty of Medicine https://orcid.org/0000-0001-9924-9727

\section{Walaa Shabana} \\ Mansoura University Faculty of Medicine
}

Ahmed Mohamed El Nakib

Mansoura University Faculty of Medicine

Mostafa Abdelsalam

Mansoura University Faculty of Medicine

Ahmed Abdelwahab

Mansoura University Faculty of Medicine

Ahmad S. Hasan

Mansoura University Faculty of Medicine

Rasha Elzehery

Mansoura University Faculty of Medicine

Rania Elhelaly

Mansoura University Faculty of Medicine

Aya Ahmed Fathy

Mansoura University Faculty of Medicine

Sally Abdallah Mostafa

Mansoura University Faculty of Medicine

Ahmed $\mathrm{H}$. Yassen

Mansoura University Faculty of Medicine

\section{Research Article}

Keywords: Advanced glycation end products, Chronic hepatitis C, cirrhosis, hepatocellular carcinoma, direct-acting antivirals

Posted Date: June 17th, 2021

DOl: https://doi.org/10.21203/rs.3.rs-619509/v1 
License: (c) (i) This work is licensed under a Creative Commons Attribution 4.0 International License. Read Full License 


\section{Abstract}

\section{Background:}

The advanced glycation end products (AGEs) have been implicated in different diseases' pathogenesis, but their role in hepatocellular carcinoma (HCC) is still a matter of debate. This study aims to investigate the association of AGEs with HCC development in patients with cirrhosis.

\section{Methods:}

Only 153 of the 181 non-diabetic patients with cirrhosis were consecutively involved in this pilot cohort prospective study, along with 34 healthy control participants. Demographic characteristics, biochemical parameters, clinical data, and AGEs levels in all subjects at the starting point and every year after that for two years were assessed. Multivariable Cox regression analysis was used to settle variables that could predict HCC development within this period.

\section{Results:}

HCC developed in 13 (8.5\%) patients. Univariate Cox regression analysis reported that age $(P=0.043)$, treatment with direct-acting antivirals (DAAs) $(P=0.021)$, and AGEs levels $(P=0.04)$ were related to HCC development. After adjusting multiple confounders, the multivariable Cox regression model has revealed that treatment with DAAs and AGEs were the powerful parameters related to the HCC occurrence (all $P<0.05)$. AGEs at a cutoff value of more than $79.6 \mathrm{ng} / \mathrm{ml}$ had $100 \%$ sensitivity, $96.4 \%$ specificity, and 0.999 area under the curve (all $\mathrm{P}<0.001$ ), using the receiver operating characteristic curve, for prediction of HCC development.

\section{Conclusion:}

This work suggests that AGEs are associated with an increased incidence of HCC, particularly in cirrhosis, which is encouraging in decreasing the risk of HCC in these patients.

\section{Background}

Chronic hepatitis $\mathrm{C}$ virus (HCV) infection is a crucial factor in the etiology of hepatic fibrosis. HCV is a major environmental problem and the leading cause of chronic liver injury and neoplastic transformation. It is one of the most frequently stated problems with liver cancer and cirrhosis [1].

Hepatocellular carcinoma (HCC) is one of the most widespread cancers and causes tumor-related mortality [2]. That is why the chronic liver disease in many HCC patients resulted from HCV or hepatitis B virus (HBV) infections [1]. Since the detailed pathogenetic mechanisms of HCC remain unclear, several studies are investigating new pathways. 
Advanced glycation end products (AGEs), a heterogeneous cluster of irreversible reactive end products created by oxidation of lipids and proteins, and non-enzymatic glycation, have been embroiled in the pathogenesis of numerous disorders [4-7] because they stimulate the oxidative stress generation and consequently induce inflammation [3].

There is accumulating evidence to display that AGEs participate in the pathogenesis of various disorders such as alcoholic liver injury, diabetic vascular complications, Alzheimer's disease, osteoporosis, and nonalcoholic steatohepatitis (NASH), cancer growth, and metastasis [8-13].

As mentioned in the literature review, there is a great deal of attention to the role of AGEs in cancer progression and initiation. Several reports have shown that AGEs have an attainable function in cancer invasion, migration, proliferation, and survival in prostate, lung cancer cell lines, and breast [14-16]. To date, far too little attention is paid to human researches. The higher rate of AGEs accretion is described in cancerous lesions compared to benign tissues [17].

These remarks directed us to hypothesize that AGEs could also participate in HCC pathogenesis, particularly in those with cirrhosis. To date, there is almost no evidence associating AGE with HCC occurrence. This study explores the relationship of AGEs with the development of HCC in patients with liver cirrhosis.

\section{Methods}

This cohort pilot single-center prospective study was accomplished at the Department of Tropical Medicine (Mansoura University-Egypt) between September 2015 and November 2019. We registered 289 consecutive patients with liver cirrhosis examined in our department. Only 181 patients fulfilled the inclusion criteria and were involved in this study. Patients' hematological, biochemical, clinical, and demographic data were appraised at the starting point and during this study.

Criteria for selecting the subjects were as follows; patients whom 1) aged $\geq 18$ years, and 2) had liver cirrhosis.

The exclusion criteria were 1) liver cirrhosis due to autoimmune hepatitis, HBV, NASH, and cholestatic or metabolic liver diseases, 2) alcoholic liver disease, 3) lactation and pregnancy, 4) hematologic disorders and kidney diseases; 5) pancreatitis, 6) diabetes mellitus 7) smoking, 8) peritoneal carcinomatosis, 9) osteoporosis, 10) abdominal tuberculosis, 11) uncontrolled thyroid disorders, 12) cancers including HCC at baseline 13) bone marrow suppression, 14) collagen vascular diseases, 15) heart failure, 16) Alzheimer's disease or cerebrovascular accident, 17) immunosuppressive agents administration, 18) missing patient's data, and 19) usage of anticoagulant or antiplatelet treatment, oral contraceptive drugs, hepatotoxic drugs, and NSAIDs.

The control group involved 34 healthy control subjects who were age- and sex-matched (female $/ \mathrm{male}=$ 
The starting point records were gathered within seven days from the time of registration. The end-ofstudy records were picked up in the last seven days of the first and second follow up years. By the end of the study; biochemical results, radiological findings, and clinical examination of the patients did not display any troubles that were not documented at the onset of this work affecting the follow-up variables in the subjects' fitness.

\section{Diagnosis of liver cirrhosis and its complications}

We assessed liver cirrhosis by unequivocal biochemical results, clinical assessment, elastography, histopathological evaluation of hepatic tissue, abdominal ultrasonography (US), or endoscopic findings suggestive of portal hypertension plus stigmata of chronic liver disease [18]. The severity of cirrhosis was evaluated based on the Model For End-Stage Liver Disease (MELD) scoring system [19] and the ChildTurcotte Pugh (CTP) classification.

Complications of liver cirrhosis were managed according to the standardized therapeutic methods during the study period [20].

\section{Diagnosis of HCC}

In all patients with cirrhosis, alpha-fetoprotein (AFP) and US- which are considered noninvasive diagnostic tools, especially for earlier stages of HCC- were performed every 3-6 months for surveillance purposes. HCC was confirmed if two imaging instances showed a focal hepatic lesion $>2 \mathrm{~cm}$ in diameter with highlights of arterial hypervascularization or solitary radiologic finding with these highlights conjoined with a serum AFP level of $>400 \mathrm{ng} / \mathrm{ml}$ [21]. Management and surveillance of individuals with HCC were achieved according to clinical practice guidelines for hepatocellular carcinoma [2].

\section{Treatment}

According to EASL recommendations [22], individuals with CTP-B and CTP-A cirrhosis, either naive patients or treatment-experienced- who had not attained sustained virologic response (SVR) after being treated with pegylated interferon (Peg IFN)/Sofosbuvir (SOF) or with Peg IFN and ribavirin (RBV)- or those treated with RBV/SOF only, were treated based on the study practice.

This study protocol was designed according to EASL guidelines for therapy of HCV, 2015 [22]. Patients infected with HCV (genotype IV) received therapy with DCV $(60 \mathrm{mg})$ and SOF $(400 \mathrm{mg})$ once daily for 12 weeks, in addition to RBV daily according to their weight, i.e., $1200 \mathrm{mg}$ for patients weighing $\geq 75 \mathrm{~kg}$ or $1000 \mathrm{mg}$ for patients weighing $<75 \mathrm{~kg}$. The dose of RBV was adjusted according to the estimated glomerular filtration rate (eGFR) [23]. In subjects with contraindications to the use of RBV, the duration of therapy was extended to 24 weeks [22].

Treatment-experienced individuals were retreated with a combination of DCV plus SOF for 24 weeks without RBV or 12 weeks with RBV [22] 
HCV RNA level was assessed at baseline, at the end of therapy (12 or 24 weeks), and 12 weeks after finishing therapy using the Roche COBAS Taq Man HCV assay version 2.0 (detection limit is $15 \mathrm{IU} / \mathrm{mL}$ ). Relapse is defined as detectable HCV RNA level during follow-up in a patient with a previously undetected level at the end of the therapy, and virological failure is referred to as nonresponse where HCV RNA levels are still detected at the end of the therapy. The primary virological response was the accomplishment of SVR12, described as the concentration in serum lower than $15 \mathrm{IU} / \mathrm{mL}$ [23].

The levels of AGEs were measured at the starting point and 12 weeks after finishing therapy.

\section{Data collection}

Qualified examiners congregated data. In order to identify these data, they asked the participants to finish a standardized, self-validated questionnaire. These queries have provided us with info about employment, marital status, alcohol consumption, and medical history, particularly malignancy, diabetes, and smoking habits, alongside medication history. BMI was calculated as weight $(\mathrm{kg})$ divided by the square of height $\left(\mathrm{m}^{2}\right)$.

\section{Sampling}

Fresh venous blood samples $(6 \mathrm{~mL})$ were collected from all subjects after overnight fasting $[4 \mathrm{~mL}$ with no anticoagulants for serum testing and $2 \mathrm{~mL}$ on EDTA for hemogram]. The mixture was centrifuged for 10 min at 1000-3000 RPM. The serum samples were then divided into aliquots and frozen at $-20 \circ \mathrm{C}$ until subsequent estimations.

\section{Methodology}

Serum creatinine and liver function tests were assessed on the Dimension Xpand Plus Chemistry Analyzer utilizing respective kits (Siemens Technology, Princeton, New Jersey). A full hemogram was evaluated by the CELL-DYN Emerald cell counter (Abbott, Wiesbaden, Germany). Serum cholesterol and triglycerides (TG) were measured using kits supplied by Spinreact [Sant Esteve De Bas (GI), Spain]. Serum AFP was evaluated by chemiluminescent immunometric technique on the Immulite 2000 system (Siemens Medical Solutions Diagnostics, Los Angeles, California, USA). The eGFR was estimated based on the next formula: $186 \times\left(\frac{\text { Creatinine }}{88.4}\right)^{-1.154} \times$ Age $^{-0.203} \times(1.210$ ifblack $) \times(0.742$ iffemale $)$ [24]. Quantitative assessments of serum AGEs were measured by ELISA kit (MyBioSource, San Diego, CA 92195 - 3308, USA, Cat No. MBS267540).

\section{Detection of HCV Genotype IV}

Hepatitis C viral RNA was measured in patients' sera by QIAamp Viral RNA Mini Kit (Qiagen, Hilden, 


\section{Ethics}

Mansoura Institutional Review Board reviewed and accepted all procedures in this study protocol. Moreover, all participants gave informed consent before the onset of this study. This work was held according to the Helsinki Declaration's rules. (Proposal Code : R.20.05.844.1R1)

\section{Statistical analysis}

Data management and analysis were performed using the Social Package of Statistical Science (SPSS) software version 20 (SPSS Inc., Chicago, IL, USA). Quantitative data and non-normally distributed continuous are designated as mean \pm SD and Range or Interquartile range correspondingly. Student t-test, Mann-Whitney $\mathrm{U}$ test, and Chi-square test were used for normally distributed data, non-normally distributed continuous data, and categorical data, correspondingly. The relation between AGEs level and other parameters was executed by Spearman's correlation analysis. At univariate analysis, parameters with a $P$ value less than 0.05 were combined in the multivariable Cox regression analysis. Multivariable and univariate Cox regression models were calculated to reveal the independent factors related to predicting HCC. The area under the curve (AUC) and receiver operating characteristic curve (ROC) were applied, and the best cutoff values were estimated to expect the development of HCC. A two-tailed $P$ value of less than 0.05 was considered significant.

\section{Results}

\section{Patient characteristics}

One hundred fifty-three patients joined this study out of the one hundred eighty-one who fulfilled the inclusion criteria and were initially registered. Eighteen out of the involved one hundred eighty-one patients in this study died from complications of cirrhosis, e.g., hepatic encephalopathy $(n=4)$, massive uncontrolled GIT bleeding $(n=10)$, and hepatorenal syndrome $(n=4)$, and we lost ten patients during the follow-up period as displayed in Fig. 1. Table 1 provides the results obtained from the preliminary analysis of the enrolled individuals' clinical, demographic, and biochemical characteristics at baseline.

Patients displayed a statistically significant increase in AST, ALP, ALT, GGT, serum creatinine, serum bilirubin, HOMA-IR, INR, AFP, and AGEs compared to healthy subjects (all $p<0.05$ ), and a statistically significant decrease in WBCs, hemoglobin, serum albumin, eGFR, and platelet count compared to healthy subjects $(p<0.05)$.

After the primary assessment at baseline by biochemical and hematological blood tests, the participants were followed up every year for two years.

Out of all the patients assessed during the follow-up period $(n=153)$, thirteen patients $(8.5 \%)$ developed HCC. Figure 2 shows serum levels of AGEs in patients with HCC compared to patients without HCC. 
Regarding the control group, there were no statistically significant differences in the levels of AGEs between the starting point and at the end-of-study (15.3 \pm 2.2 vs. $16.2 \pm 2.3 ; P=0.09)$, and none of them develops HCC during the follow-up period.

\section{Correlation between demographic and biochemical parameters with AGEs of the studied patients:}

Spearman's correlation analysis revealed there was a significant positive correlation between serum AGEs and fibrinogen, age, AFP, and HOMA-IR ( $r h o=0.37, P<0.001$; $r h o=0.41, P<0.001$; rho $=0.71, P<0.001$; and $r h o=0.81, P<0.001$ individually).

\section{Multivariable and univariate Cox regression models predicting HCC within the two years follow-up period:}

Table 2 presents an overview of patients' biochemical, clinical, and demographic features without and with HCC.

There is no significant difference in total cholesterol, hemoglobin, sex, age, WBCs, serum triglyceride, GGT, INR, serum bilirubin, serum creatinine, CTP classification, MELD score, eGFR or HOMA-IR between the two groups (all $P>0.05$ ). Univariate Cox regression analysis showed that treatment with DAAs, AGEs, and age are statistically significant between the two groups (all $P<0.05)$ in Table 3.

The multivariable Cox regression analysis model outcomes were reassessed, after adjusting multiple confounders, applying the formerly described variables at baseline associated with the development of HCC during the two-year follow-up period. This test showed that the only parameters independently related to the development of HCC are treatment with DAAs and AGEs (Table 3).

Using the ROC curve, at a cutoff value of $>79.6 \mathrm{ng} / \mathrm{ml}$, AGEs had $100 \%$ sensitivity, $96.4 \%$ specificity, 0.999 AUC, $100 \%$ negative predictive value, $72.2 \%$ positive predictive value, and $P<0.001$ for prediction of HCC, as presented in Fig. 3.

\section{HCC managements:}

Patients who developed HCC $(n=13)$ received therapy. Six patients $(46.1 \%)$ undergone hepatic resection, five patients (38.5\%) had transcatheter arterial chemoembolization (TACE), and two patients $(15.4 \%)$ had liver transplantation.

All patients were followed-up regularly (mean $26 \pm 6$ months) to check the effectiveness of different therapy modalities.

Regarding AGEs, there was a significant reduction of serum AGE at baseline and 3-months after therapy as follows (130.6 \pm 17.7 vs. $66.84 \pm 7.68 ; P<0.001)$. 
Two patients developed postembolization syndrome and were controlled by analgesics and antibiotics. Of six patients with hepatic resection, only two patients developed ascites and were controlled by diuretics and albumin infusion. Recurrence of HCC was not detected after various therapy modalities for the whole two-year follow-up period.

\section{Therapeutic findings:}

According to our study protocol, participants with CTP-B $(n=52)$ and CTP-A $(n=62)$ cirrhosis received treatment, while the rest of the patients $(n=39)$ refused to take this therapy. SVR showed in $90(79 \%)$ patients. No significant difference was detected in AGEs after completion of therapy vs. at baseline (73.8 \pm 20.8 vs. $78.6 \pm 21.4 ; P=0.1)$.

AGEs presented no significant differences at starting point and at the end of treatment regarding relapse $(n=9)(76.5 \pm 20.2$ vs. $80.6 \pm 21.2 ; P=0.68)$, non-responder $(n=15)(78.6 \pm 21.5$ vs. $82.1 \pm 21.8 ; P=0.66)$, and SVR $(n=90)(75.6 \pm 21.3$ vs. $80.2 \pm 21.6 ; P=0.15)$

There was no statistically significant change between patients who did not receive treatment and those who did (1/39 vs. $12 / 114 ; P=0.127)$ correspondingly regarding the development of HCC.

\section{Safety and tolerability}

The most popular side effects were pruritus ( $6.5 \%$ and $11.5 \%)$, headache $(6.5 \%$ and $15.4 \%)$, hyperbilirubinemia (11.3\% and $23.1 \%)$, RBV dose reductions ( $4.8 \%$ and $9.6 \%)$, anaemia $(14.5 \%$ and $26.9 \%$ ), and fatigue ( $8 \%$ and $28.8 \%$ ) in CTP-A and CTP-B patients; correspondingly.

We registered critical adverse events in CTP-B cirrhotic patients more than CTPA; ( $3.2 \%$ and $7.7 \%$ ) had GIT bleeding, (1.6\% and $5.8 \%)$ had hepatic encephalopathy, (6.5\% and $9.6 \%)$ developed ascites, $(6.5 \%$ and 9.6\%) had HCC, and (0.0\% and 3.8\%), had renal impairment in CTP-A and CTP-B respectively.

\section{Discussion}

The interaction of the receptor for advanced glycation end products (RAGE) with AGEs is believed to cause chronic pathophysiology through various processes [26]. The relationship between the development of HCC and RAGE activation achieved consideration as a consequence of the role of the liver in the metabolism of AGE [28]. Experimental reports also proposed the RAGE-AGE axis role in initiating different hepatic disorders and tumorigenesis $[9,28]$.

The most significant finding in our patients was that increased AGEs levels can be deemed an independent variable for predicting HCC occurrence.

AGEs-provoked reactive oxygen species (ROS) release might intercede via nuclear factor-kappa (NF-KB) independent and/or dependent manners. Stimulated NF-KB initiates tumor necrosis factor-alpha (TNF-a) release, which unites to tumor necrosis factor receptor 1 (TNFR-1) and then produces ROS [29, 30], which 
molecules, for example, stress-activated protein kinase/c-Jun N-terminal kinase, mitogen-activated protein kinases (MAPK), as p38, and extracellular signal-regulated kinase 1 are included in the AGEstimulated TNF-a production and ROS release [31]. These abnormalities can provoke the progression and development of $\mathrm{HCC}[32,33]$.

Furthermore, DNA's oxidative injuries lead to mutagenic and carcinogenic effects by dividing cells with unpaired or mis-repaired injuries, which finally provoke the development and progression of HCC [34].

There is a striking observation, which is a sharp decline in serum AGEs after therapy for HCC. This may perhaps elucidate the role of RAGE in the pathogenesis of HCC, especially in altering carcinogenic signaling in the cancer microenvironment $[14,35,36]$. Takino et al. [14] issued that the anti-RAGE antibody therapy can prevent cancer development, protract survival rates, and suppress spontaneous lung metastases. Hepatic tissue samples of primary HCC patients detected markedly elevated levels of RAGE mRNA. This explains the possible role of RAGE in HCC propagation [36]. Chen et al. [37] recorded repeatedly amplified expressions of RAGE, high mobility group box-1 (HMGB1), and extracellular HMGB in keeping with cell metastasis potentials in various HCC cell lines. The RAGE-HMGB1 axis encourages cell division, immigration, and incursion and raises the level of NF-KB in HCC cell lines [37]. Additionally, the precise downstream signaling ways of the RAGE-HMGB1 axis in the evolution of HCC calls for additional studies. A decrease in RAGE holds up the onset of malignant conversion in the double knockout HCC mice model, which draws attention to the role of RAGE in the development of HCC [38].

The most prominent finding to emerge from the analysis is that therapy with DAA can be deemed an independent variable for predicting HCC occurrence.

This relationship may partly be explained by an immunological reaction that explains the high percentage of HCC incidence with patients receiving DAA. HCV eradication leads to decreased inflammation levels leading to decreased cancer immunosurveillance by the patient, and encourages HCC development [39, 40]. Furthermore, a decrease in natural killer group 2 member $D$, which is linked to tumor immunity [41], and increased serum levels of vascular endothelial growth factor throughout the DAA therapy have both been found [42]. Zanetto et al. found that cancer growth in HCC patients while on the waiting list for LT is nearly the same before versus after DAA therapy [43]. It is not evident if DAA boosts the malignant potential of HCC. We can say that, while DAA may not directly advance HCC, it causes an increase in the rate of incidence and number of HCCs during DAA therapy by an indirect mean through the inhibition of the inflammatory process.

If HCV triggered the elevation in the levels of AGE [44], they should have gotten back to their average values after therapy with DAAs. Nonetheless, we did not detect any diminish in the estimations of their values after follow-up and treatment compared to the baseline values for these patients. This implies that cirrhosis is the main cause behind this increase.

The RAGE-AGE axis is a principal etiology in the activation of HSC and the resulting liver cirrhosis. 
controlling high glucose, and oxidant supplement digestion [45] is an auguring approach to reducing the hazard of liver cirrhosis and HCC in CHC patients, particularly with raised AGEs.

To the best of our knowledge, this study is the first to contribute to this growing area of research by exploring the impact of AGEs in such patients. These results have significant effects in the understanding of how AGEs were implicated in HCC development.

To the best of our insight from the accessible results, we advocate further exploitation of inflammatory signaling cascades, MAPK, and NF-KB activation as a possible target to establish a direct linkage between glycation and HCC and study the effect of the anti-RAGE antibody treatment in HCC-related cirrhosis.

The precise mechanism of AGEs in cirrhosis still needs clarification. These findings suggest several pathways for AGEs in the pathogenesis of HCC. The findings of this study have several important implications for future practice. Further research in this field would be of great help in understanding the pathogenesis of HCC and the effect of the anti-RAGE antibody therapy in such patients

The generalizability of these results is subject to certain limitations-first, small sample size. Second, a single-center study with a follow-up period of only two years could not reveal the levels of immunological or cytokines mediators. Third, the etiology of cirrhosis is only the hepatitis $C$ virus. Fourth, overfitting the learning curves with high AUC was noted, and it is an abstruse drawback. Model validation is frequently

applied to control and assess this problem. Conversely, these methods need someone to hold or collect a considerable amount of records for validation and are rarely utilized in research comprising human individuals, where data collection is usually extraordinarily costly [46]. Fifth, the difference between the two sample sizes should be discussed because this could influence a potential beta error. So, the authors wanted to include as many patients as possible, and that is why we enrolled fewer subjects in the control group as this study was self-funded. In Egypt, funding opportunities are rare to come by. This study was self-funded due to financial difficulties as we are struggling with the funding resources and availability. This was the maximum number of patients that we can afford to enroll in our study. Lastly, the diagnosis of HCC depends mainly on radiological and biochemical findings, not histopathological evaluation. The authors recommend multiple studies to verify these results on a larger scale.

\section{Conclusions}

AGEs were obviously associated with an increased incidence of HCC, particularly in patients with liver cirrhosis. This may be an implying approach to reduce the hazard of HCC and liver cirrhosis in those patients.

\section{List Of Abbreviations}

AGEs, advanced glycation end products; HCC, hepatocellular carcinoma; AFP, alpha-fetoprotein; DAAs, Loading [MathJax]/jax/output/CommonHTML/fonts/TeX/fontdata.js ptor for Advanced Glycation Endproducts; GIT, 
gastrointestinal tract; BMI, Basal metabolic index; NASH, non-alcoholic steatohepatitis; HCV, hepatitis C virus; DCV, daclatasvir; SOF, Sofosbuvir; MELD, Model for End-Stage Liver Disease; CTP, Child-Turcotte Pugh.

\section{Declarations}

\section{Ethics approval and consent to participate:}

Mansoura Institutional Review Board reviewed and accepted all procedures in this study protocol. Moreover, all participants gave informed consent before the onset of this study. This work was held according to the Helsinki Declaration's rules. (Proposal Code: R.20.05.844.1R1)

Consent for publication:

Not applicable

\section{Availability of data and materials:}

The raw data supporting the conclusions of this manuscript will be made available by the authors, without undue reservation, to any qualified researcher.

\section{Competing interests:}

The authors declare that they have no competing interests

\section{Funding:}

None

\section{Authors' contributions:}

All the authors have accepted responsibility for the entire content of this submitted manuscript and approved submission.

Guarantor of the article: Ahmed Abdel-Razik.

Ahmed Abdel-Razik, Walaa Shabana, and Ahmed Mohamed El Nakib contributed to the study design and concept, conducted the literature search, supervised the study, and wrote the manuscript; Mostafa Abdelsalam, Ahmed Abdelwahab and Ahmed H. Yassen made the tables and figures and contributed to the data analysis; Rania Elhelaly, Rasha Elzehery, and Sally Abdallah Mostafa contributed to the collection of patients' samples and medical information; as well as contributed to the analysis of data and acquisition; and contributed to the acquisition of data; Ahmed S. Hasan contributed to the study concept and critically revised the manuscript; Aya Ahmed Fathy performed the statistical analysis. 
All authors approved the final version of the article, including the authorship list

\section{Acknowledgments:}

The authors thank the staff and patients of the Tropical Medicine Department and the lab specialists for their significant aid.

\section{References}

1. Perz JF, Armstrong GL, Farrington LA, Hutin YJ, Bell BP. The contributions of hepatitis B virus and hepatitis $C$ virus infections to cirrhosis and primary liver cancer worldwide. J Hepatol. 2006;45:52938.

2. Clinical Practice Guidelines for Hepatocellular. Carcinoma Differ between Japan, United States, and Europe. Liver Cancer. 2015;4:85-95.

3. Piarulli F, Sartore G, Lapolla A. Glyco-oxidation and cardiovascular complications in type 2 diabetes: a clinical update. Acta Diabetol. 2013;50:101-10.

4. Zhou G, Li C, Cai L. Advanced glycation end-products induce connective tissue growth factormediated renal fibrosis predominantly through transforming growth factor beta-independent pathway. Am J Pathol. 2004;165:2033-43.

5. Hyogo H, Yamagishi S, Iwamoto K, Arihiro K, Takeuchi M, Sato T, et al. Elevated levels of serum advanced glycation end products in patients with non-alcoholic steatohepatitis. J Gastroenterol Hepatol. 2007;22:1112-9.

6. Marta K, Tomas Z, Petr P, Pavel S, Martin B, Soukupová J, et al. Advanced glycation end-products in patients with chronic alcohol misuse. Alcohol Alcohol. 2004;39:316-20.

7. Abdel-Razik A, Mousa N, Zakaria S, Abdelsalam M, Eissa M, Abd El-Ghany MI, Hasan AS, Elhelaly R, Elzehery R, El-Wakeel N, Eldars W. Advanced Glycation End Products as a Predictor of Diabetes Mellitus in Chronic Hepatitis C-Related Cirrhosis. Front Med. 2020;7:588519.

8. Yamagishi S, Maeda S, Matsui T, Ueda S, Fukami K, Okuda S. Role of advanced glycation end products (AGEs) and oxidative stress in vascular complications in diabetes. Biochim Biophys Acta. 2012;1820:663-71.

9. Hyogo H, Yamagishi S. Advanced glycation end products (AGEs) and their involvement in liver disease. Curr Pharm Des. 2008;14:969-72.

10. Takeuchi M, Sakasai-Sakai A, Takata T, Ueda T, Takino J, Tsutsumi M, et al. Serum levels of toxic AGEs (TAGE) may be a promising novel biomarker in development and progression of NASH. Med Hypotheses. 2015;84(5):490-3.

11. Hayashi N, George J, Takeuchi M, Fukumura A, Toshikuni N, Arisawa T, et al. Acetaldehyde-derived advanced glycation end-products promote alcoholic liver disease. PLoS One. 2013;8:e70034.

12. Takino J, Yamagishi S, Takeuchi M. Glycer-AGEs-RAGE signaling enhances the angiogenic potential 
2012;18:1781-8.

13. Takeuchi M, Yamagishi S. Possible involvement of advanced glycation end-products (AGEs) in the pathogenesis of Alzheimer's disease. Curr Pharm Des. 2008;14:973-8.

14. Takino J, Yamagishi S, Takeuchi M. Cancer malignancy is enhanced by glyceraldehyde-derived advanced glycation end-products. J Oncol. 2010;2010:739852.

15. Rodriguez-Teja M, Gronau JH, Breit C, Zhang YZ, Minamidate A, Caley MP, et al. AGE-modified basement membrane cooperates with Endo180 to promote epithelial cell invasiveness and decrease prostate cancer survival. J Pathol. 2015;235:581-92.

16. Sharaf H, Matou-Nasri S, Wang Q, Rabhan Z, Al-Eidi H, Al Abdulrahman A, et al. Advanced glycation endproducts increase proliferation, migration and invasion of the breast cancer cell line MDA-MB231. Biochim. Biophys Acta. 2015;1852:429-41.

17. Palimeri S, Palioura E, Diamanti-Kandarakis E. Current perspectives on the health risks associated with the consumption of advanced glycation end products: recommendations for dietary management. Diabetes Metab Syndr Obes. 2015;8:415-26.

18. Abdel-Razik A, Mousa N, Elhelaly R, Elzehery R, Hasan AS, Abdelsalam M, et al. Helicobacter pylori as an Initiating Factor of Complications in Patients With Cirrhosis: A Single-Center Observational Study. Front Med. 2020;7:96.

19. Kamath PS, Wiesner RH, Malinchoc M, Kremers W, Therneau TM, Kosberg CL, et al. A model to predict survival in patients with end-stage liver disease. Hepatology. 2001;33:464-70.

20. Cardenas A, Ginès $P$. Management of complications of cirrhosis in patients awaiting liver transplantation. J Hepatol. 2005;42:124-33.

21. Wang $\mathrm{CH}$, Wey KC, Mo LR, Chang KK, Lin RC, Kuo JJ. Current trends and recent advances in diagnosis, therapy, and prevention of hepatocellular carcinoma. Asian Pac J Cancer Prev. 2015;16:3595-604.

22. European Association for Study of Liver. EASL Recommendations on Treatment of Hepatitis C 2015. J Hepatol. 2015;63:199-236.

23. El-Khayat H, Fouad Y, Mohamed HI, El-Amin H, Kamal EM, Maher M, et al. Sofosbuvir plus daclatasvir with or without ribavirin in 551 patients with hepatitis C-related cirrhosis, genotype 4. Aliment Pharmacol Ther. 2018;47:674-9.

24. Levey AS, Bosch JP, Lewis JB, Greene T, Rogers N, Roth D. A more accurate method to estimate glomerular filtration rate from serum creatinine: a new prediction equation. Modification of Diet in Renal Disease Study Group. Ann Intern Med. 1999;130:461-70.

25. Ohno O, Mizokami M, Wu RR, Saleh MG, Ohba K, Orito E, et al. New hepatitis C virus (HCV) genotyping system that allows for identification of HCV genotypes 1a, 1b, 2a, 2b, 3a, 3b, 4, 5a, and 6a. J Clin Microbiol. 1997;35:201-7.

26. Tabrez S, Al-Shali KZ, Ahmad S. Lycopene powers the inhibition of glycation-induced diabetic nephropathy: a novel approach to halt the AGE-RAGE axis menace. Biofactors. 2015;41:372-81. 
27. Su SC, Hsieh MJ, Chou YE, Fan WL, Yeh CB, Yang SF. Effects of RAGE Gene Polymorphisms on the Risk and Progression of Hepatocellular Carcinoma. Medicine. 2015;94:e1396.

28. Hiwatashi K, Ueno S, Abeyama K, Kubo F, Sakoda M, Maruyama I, et al. A novel function of the receptor for advanced glycation end-products (RAGE) in association with tumorigenesis and tumor differentiation of HCC. Ann Surg Oncol. 2008;15:923-33.

29. Neumann A, Schinzel R, Palm D, Riederer P, Münch G. High molecular weight hyaluronic acid inhibits advanced glycation endproduct-induced NF-kappaB activation and cytokine expression. FEBS Lett. 1999;453:283-7.

30. Janssen-Heininger YM, Poynter ME, Baeuerle PA. Recent advances towards understanding redox mechanisms in the activation of nuclear factor kappaB. Free Radic Biol Med. 2000 May;1:28:131727.

31. Requena P, Daddaoua A, Guadix E, Zarzuelo A, Suárez MD, Sánchez de Medina F, et al. Bovine glycomacropeptide induces cytokine production in human monocytes through the stimulation of the MAPK and the NF-kappaB signal transduction pathways. Br J Pharmacol. 2009;157:1232-40.

32. Muriel P. Role of free radicals in liver diseases. Hepatol Int. 2009;3:526-36.

33. Zhao HF, Wang J, Tony To SS. The phosphatidylinositol 3-kinase/Akt and c-Jun N-terminal kinase signaling in cancer: Alliance or contradiction? (Review). Int J Oncol. 2015;47:429-36.

34. Yang SF, Chang CW, Wei RJ, Shiue YL, Wang SN, Yeh YT. Involvement of DNA damage response pathways in hepatocellular carcinoma. Biomed Res Int. 2014;2014:153867.

35. Pusterla T, Nèmeth J, Stein I, Wiechert L, Knigin D, Marhenke S, et al. Receptor for advanced glycation endproducts (RAGE) is a key regulator of oval cell activation and inflammation-associated liver carcinogenesis in mice. Hepatology. 2013;58:363-73.

36. Yaser AM, Huang Y, Zhou RR, Hu GS, Xiao MF, Huang ZB, et al. The Role of receptor for Advanced Glycation End Products (RAGE) in the proliferation of hepatocellular carcinoma. Int J Mol Sci. 2012;13:5982-97.

37. Chen RC, Yi PP, Zhou RR, Xiao MF, Huang ZB, Tang DL, et al. The role of HMGB1-RAGE axis in migration and invasion of hepatocellular carcinoma cell lines. Mol Cell Biochem. 2014;390:271-80.

38. Pikarsky E, Porat RM, Stein I, Abramovitch R, Amit S, Kasem S, Gutkovich-Pyest E, Urieli-Shoval S, Galun E, Ben-Neriah Y. NF-kappaB functions as a tumour promoter in inflammation-associated cancer. Nature. 2004;431:461-6.

39. Reig M, Mariño Z, Perelló C, Iñarrairaegui M, Ribeiro A, Lens S, et al. Unexpected high rate of early tumor recurrence in patients with HCV-related HCC undergoing interferon-free therapy. J Hepatol. 2016;65:719-26.

40. Nault JC, Colombo M. Hepatocellular carcinoma and direct acting antiviral treatments: Controversy after the revolution. J Hepatol. 2016;65:663-5.

41. Chu PS, Nakamoto N, Taniki N, Ojiro K, Amiya T, Makita Y, et al. On-treatment decrease of NKG2D correlates to early emergence of clinically evident hepatocellular carcinoma after interferon-free 
42. Villani R, Facciorusso A, Bellanti F, Tamborra R, Piscazzi A, Landriscina M, et al. DAAs Rapidly Reduce Inflammation but Increase Serum VEGF Level: A Rationale for Tumor Risk during Anti-HCV Treatment. PLoS One. 2016;11:e0167934.

43. Zanetto A, Shalaby S, Vitale A, Mescoli C, Ferrarese A, Gambato M, et al. Dropout rate from the liver transplant waiting list because of hepatocellular carcinoma progression in hepatitis $C$ virus-infected patients treated with direct-acting antivirals. Liver Transpl. 2017;23:1103-12.

44. He Y, Zhu J, Huang Y, Gao H, Zhao Y. Advanced glycation end product (AGE)-induced hepatic stellate cell activation via autophagy contributes to hepatitis C-related fibrosis. Acta Diabetol. 2015;52:95969.

45. Raffaelli F, Vignini A, Giulietti A, Alidori A, Borroni F, Sforza G, et al. In vitro effects of resveratrol on oxidative stress in diabetic platelets. Acta Diabetol. 2014 Feb;51(1):61-9.

46. Vabalas A, Gowen E, Poliakoff E, Casson AJ. Machine learning algorithm validation with a limited sample size. PLoS One. 2019;14:e0224365.

\section{Tables}


Table 1

Baseline biochemical, demographic, and clinical characteristics of enrolled participants.

\begin{tabular}{|c|c|c|c|}
\hline Characteristics & $\begin{array}{l}\text { Patients with cirrhosis } \\
(n=153)\end{array}$ & $\begin{array}{l}\text { Control group } \\
(n=34)\end{array}$ & P Value \\
\hline Age (year) & $57.81 \pm 5.4$ & $56.4 \pm 4.2$ & 0.15 \\
\hline Sex (male/female) & $99 / 54$ & $22 / 12$ & 0.57 \\
\hline Body mass index $\left(\mathrm{kg} / \mathrm{m}^{2}\right)$ & $26 \pm 1.05$ & $25.70 \pm 0.34$ & 0.1 \\
\hline \multicolumn{4}{|c|}{ Patients receiving DAA $(n=114)$} \\
\hline SVR & $90(79)$ & - & - \\
\hline Non-responder & $24(21)$ & - & - \\
\hline Patients not receiving DAA & $39(25.5)$ & - & - \\
\hline $\mathrm{Hb}(\mathrm{gm} / \mathrm{dl})$ & $9.14 \pm 0.71$ & $12.06 \pm 0.35$ & $<0.001$ \\
\hline WBCs $\left(\times 10^{3} / \mathrm{cm}^{2}\right)$ & $3.58 \pm 1.94$ & $6.3 \pm 1.54$ & $<0.001$ \\
\hline Platelet count $\left(\times 10^{3} / \mathrm{cm}^{2}\right)$ & $80.49 \pm 24.2$ & $202.53 \pm 50.92$ & $<0.001$ \\
\hline Total cholesterol (mg/dl) & $177.88 \pm 13.6$ & $174.12 \pm 10.1$ & 0.13 \\
\hline Triglyceride (mg/dl) & $123.28 \pm 16.16$ & $128.24 \pm 7.8$ & 0.08 \\
\hline AST $(U / I)$ & $41.91 \pm 14.43$ & $28.82 \pm 5.28$ & $<0.001$ \\
\hline $\operatorname{ALT}(\mathrm{U} / \mathrm{I})$ & $39.09 \pm 13.74$ & $28.4118 \pm 4.07$ & $<0.001$ \\
\hline GGT (U/I) & $38.63 \pm 10.84$ & $22.17 \pm 4.7$ & $<0.001$ \\
\hline ALP (IU/ml) & $100(93.0-110.0)$ & $53(44.7-65.2)$ & $<0.001$ \\
\hline Bilirubin (mg/dl) & $2.54 \pm 1.29$ & $0.90 \pm 0.15$ & $<0.001$ \\
\hline Albumin (g/dl) & $2.99 \pm 0.42$ & $4.17 \pm 0.18$ & $<0.001$ \\
\hline INR & $1.56 \pm 0.27$ & $0.93 \pm .08$ & $<0.001$ \\
\hline Creatinine (mg/dl) & $1.22 \pm 0.27$ & $0.89 \pm 0.16$ & $<0.001$ \\
\hline eGFR & $76.3 \pm 9.4$ & $96.3 \pm 6.2$ & $<0.001$ \\
\hline
\end{tabular}

Data were presented as mean \pm SD, median and interquartile range or $\mathrm{n}(\%)$.

SVR, sustained virological response; DAA, direct acting antiviral; AST, aspartate aminotransferase; HOMA-IR, homeostasis modelAssessment-insulin resistance, INR, international normalized ratio; FPG, fasting plasma glucose; AGEs, advanced glycation end products; ALP, alkaline phosphatase; eGFR, estimated alomerular filtration rate; WBCs, white blood cells; MELD, Model for End-Stage Liver Loading [MathJax]/jax/output/CommonHTML/fonts/TeX/fontdata.js ninotransferase. 


\begin{tabular}{|c|c|c|c|}
\hline Characteristics & $\begin{array}{l}\text { Patients with cirrhosis } \\
(n=153)\end{array}$ & $\begin{array}{l}\text { Control group } \\
(n=34)\end{array}$ & P Value \\
\hline Child-Pugh score & $7.96 \pm 2.72$ & - & - \\
\hline MELD score & $17.03 \pm 4.05$ & - & - \\
\hline $\mathrm{FPG}(\mathrm{mg} / \mathrm{dl})$ & $88.27 \pm 7.6$ & $87.88 \pm 4.9$ & 0.78 \\
\hline HOMA-IR & $3.80 \pm 0.5$ & $1.8 \pm 0.23$ & $<0.001$ \\
\hline $\operatorname{AFP}(\mathrm{ng} / \mathrm{ml})$ & $45(23-66)$ & $7(5.7-9)$ & $<0.001$ \\
\hline AGEs (ng/ml) & $73.2 \pm 19.6$ & $14.3 \pm 1.4$ & 0.001 \\
\hline \multicolumn{4}{|c|}{ Data were presented as mean $\pm S D$, median and interquartile range or $n(\%)$. } \\
\hline \multicolumn{4}{|c|}{$\begin{array}{l}\text { SVR, sustained virological response; DAA, direct acting antiviral; AST, aspartate aminotransferase; } \\
\text { HOMA-IR, homeostasis modelAssessment-insulin resistance, INR, international normalized ratio; FPG, } \\
\text { fasting plasma glucose; AGEs, advanced glycation end products; ALP, alkaline phosphatase; eGFR, } \\
\text { estimated glomerular filtration rate; WBCs, white blood cells; MELD, Model for End-Stage Liver } \\
\text { Disease; GGT, Y-glutamyl transpeptidase; ALT, alanine aminotransferase. }\end{array}$} \\
\hline
\end{tabular}


Table 2

Biochemical, demographic, and clinical characteristics of patients without and with HCC during the follow-up period

\begin{tabular}{|llll|}
\hline Characteristics & $\begin{array}{l}\text { No HCC } \\
(\mathbf{n}=140)\end{array}$ & $\begin{array}{l}\text { HCC } \\
(\mathbf{n}=13)\end{array}$ & P value \\
\hline Age (year) & $57.87 \pm 5.53$ & $57.07 \pm 4.19$ & 0.613 \\
\hline Sex (male/female) & $91 / 49$ & $8 / 5$ & 0.5 \\
\hline Body mass index (kg/m $\left.{ }^{2}\right)$ & $26.7 \pm 1.09$ & $25.9 \pm 1.03$ & 0.012 \\
\hline Patients receiving DAA & & & \\
\hline SVR & $79(56.4)$ & $11(84.6)$ & 0.049 \\
\hline Non-responder & $23(16.4)$ & $1(7.7)$ & 0.411 \\
\hline Patients not receiving DAA & $38(27.2)$ & $1(7.7)$ & 0.124 \\
\hline Hb (gm/dl) & $9.15 \pm 0.65$ & $9.14 \pm 0.7$ & 0.958 \\
\hline WBCs $\left(x 10^{3} / \mathrm{cm}{ }^{2}\right)$ & $3.59 \pm 2.03$ & $3.43 \pm 0.37$ & 0.778 \\
\hline Platelet count $\left(\times 10^{3} / \mathrm{cm}^{2}\right)$ & $57.9 \pm 21.6$ & $88.6 \pm 32.19$ & $<0.001$ \\
\hline Total cholesterol (mg/dl) & $177.55 \pm 13.85$ & $181.46 \pm 10.3$ & 0.323 \\
\hline Triglyceride (mg/dl) & $122.81 \pm 16.48$ & $128.31 \pm 11.48$ & 0.242 \\
\hline AST (U/l) & $41.09 \pm 13.55$ & $50.76 \pm 20.43$ & 0.02 \\
\hline ALT (U/l) & $38.27 \pm 12.71$ & $47.92 \pm 20.66$ & $<0.001$ \\
\hline GGT (U/l) & $38.82 \pm 11.025$ & $36.53 \pm 8.685$ & 0.468 \\
\hline ALP (IU/ml) & $100(92-108.75)$ & $110(100-122)$ & $<0.001$ \\
\hline Bilirubin (mg/dl) & $2.1(1.6-2.8)$ & $1.45(2.3-3.7)$ & 0.569 \\
\hline T protein & $1.14 \pm 0.09$ & $0.37 \pm 0.1$ & 0.001 \\
\hline Albumin (g/dl) & $2.97 \pm 0.39$ & $3.30 \pm 0.59$ & 0.704 \\
\hline INR & $1.56 \pm 0.273$ & $1.59 \pm 0.26$ & \\
\hline
\end{tabular}

Data were presented as mean $\pm S D$, median and interquartile range or $n(\%)$.

SVR, sustained virological response; DAA, direct acting antiviral; AST, aspartate aminotransferase; HOMA-IR, homeostasis modelAssessment-insulin resistance, INR, international normalized ratio; FPG, fasting plasma glucose; AGEs, advanced glycation end products; ALP, alkaline phosphatase; eGFR, estimated alomerular filtration rate; WBCs, white blood cells; MELD, Model for End-Stage Liver Loading [MathJax]/jax/output/CommonHTML/fonts/TeX/fontdata.js ninotransferase. 


\begin{tabular}{|c|c|c|c|}
\hline Characteristics & $\begin{array}{l}\text { No HCC } \\
(n=140)\end{array}$ & $\begin{array}{l}\text { HCC } \\
(n=13)\end{array}$ & $P$ value \\
\hline Creatinine (mg/dl) & $1.2 \pm 0.26$ & $1.23 \pm 0.3$ & 0.695 \\
\hline eGFR & $78.8 \pm 9.6$ & $75.4 \pm 9.2$ & 0.222 \\
\hline Child-Pugh score & $8 \pm 2.75$ & $7.6 \pm 2.46$ & 0.614 \\
\hline MELD score & $16.9 \pm 3.89$ & $17.84 \pm 5.58$ & 0.425 \\
\hline FPG (mg/dl) & $87.521 \pm 7.50$ & $96.3 \pm 3.27$ & $<0.001$ \\
\hline HOMA-IR & $3.76 \pm 0.55$ & $4.24 \pm 0.42$ & 0.003 \\
\hline AFP $(\mathrm{ng} / \mathrm{ml})$ & $24.3(23-63)$ & $44(39-400)$ & $<0.001$ \\
\hline AGEs (ng/ml) & $67.96 \pm 7.71$ & $130.6 \pm 17.8$ & $<0.001$ \\
\hline \multicolumn{4}{|c|}{ Data were presented as mean $\pm S D$, median and interquartile range or $n(\%)$. } \\
\hline \multicolumn{4}{|c|}{$\begin{array}{l}\text { SVR, sustained virological response; DAA, direct acting antiviral; AST, aspartate aminotransferase; } \\
\text { HOMA-IR, homeostasis modelAssessment-insulin resistance, INR, international normalized ratio; FPG, } \\
\text { fasting plasma glucose; AGEs, advanced glycation end products; ALP, alkaline phosphatase; eGFR, } \\
\text { estimated glomerular filtration rate; WBCs, white blood cells; MELD, Model for End-Stage Liver } \\
\text { Disease; GGT, y-glutamyl transpeptidase; ALT, alanine aminotransferase. }\end{array}$} \\
\hline
\end{tabular}

Table 3

Cox regression analysis models to predict the development of HCC in the studied patients.

\begin{tabular}{|lllllll|}
\hline Variables & \multicolumn{2}{l}{ Univariate Cox regression } & \multicolumn{3}{l|}{ Multivariable Cox regression } \\
\cline { 2 - 7 } & HR & $95 \% \mathrm{Cl}$ & P value & HR & $95 \% \mathrm{Cl}$ & P value \\
\hline Age & 0.897 & $0.739-1.005$ & 0.045 & - & - & - \\
\hline DAA & 0.058 & $0.005-0.656$ & 0.021 & 0.023 & $0.001-0.437$ & 0.012 \\
\hline AGE & 0.949 & $0.903-0.998$ & 0.04 & 0.941 & $0.889-0.995$ & 0.032 \\
\hline AGEs, advanced glycation end products; DAA, direct acting antiviral; HR, hazard ratio \\
\hline
\end{tabular}

\section{Figures}




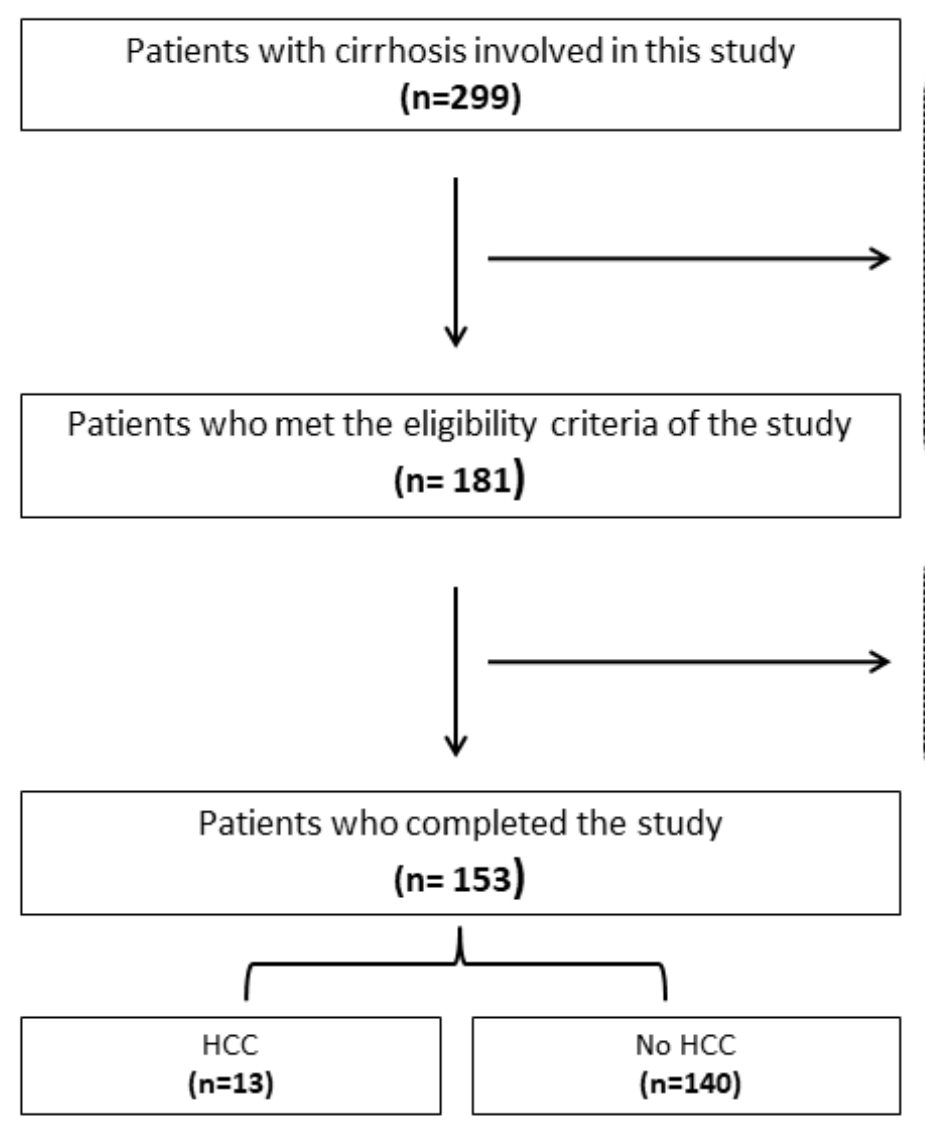

Exclusion criteria at baseline $(n=118)$

- Patients with DM and/or IGT ( $n=70)$

- Missing data $(n=9)$

- Patients with CHB-related cirrhosis $(n=8)$

- Cancers $(n=7)$

- Patients with AlH-related cirrhosis $(n=7)$

- Collagen vascular diseases $(n=4)$

- Uncontrolled thyroid disorders $(n=4)$

- Peritoneal carcinomatosis $(n=4)$

- Patient with antiplatelet drugs $(n=3)$

- Abdominal tuberculosis $(n=2)$

- Patients Missing during follow-up $(n=10)$

- Patients died from cirrhotic complications $(n=18)$

* Massive uncontrolled GIT bleeding $(n=10)$

* Hepatorenal syndrome $(n=4)$

* Hepatic encephalopathy $(n=4)$

Figure. 1 Flowchart of the patients involved in this study

HCC: hepatocellular carcinoma, DM: diabetes mellitus, IGT: impaired glucose tolerance, AIH: autoimmune hepatitis, GIT: gastrointestinal tract, CHB: chronic hepatitis B.

\section{Figure 1}

Flowchart of the patients included in this study. 


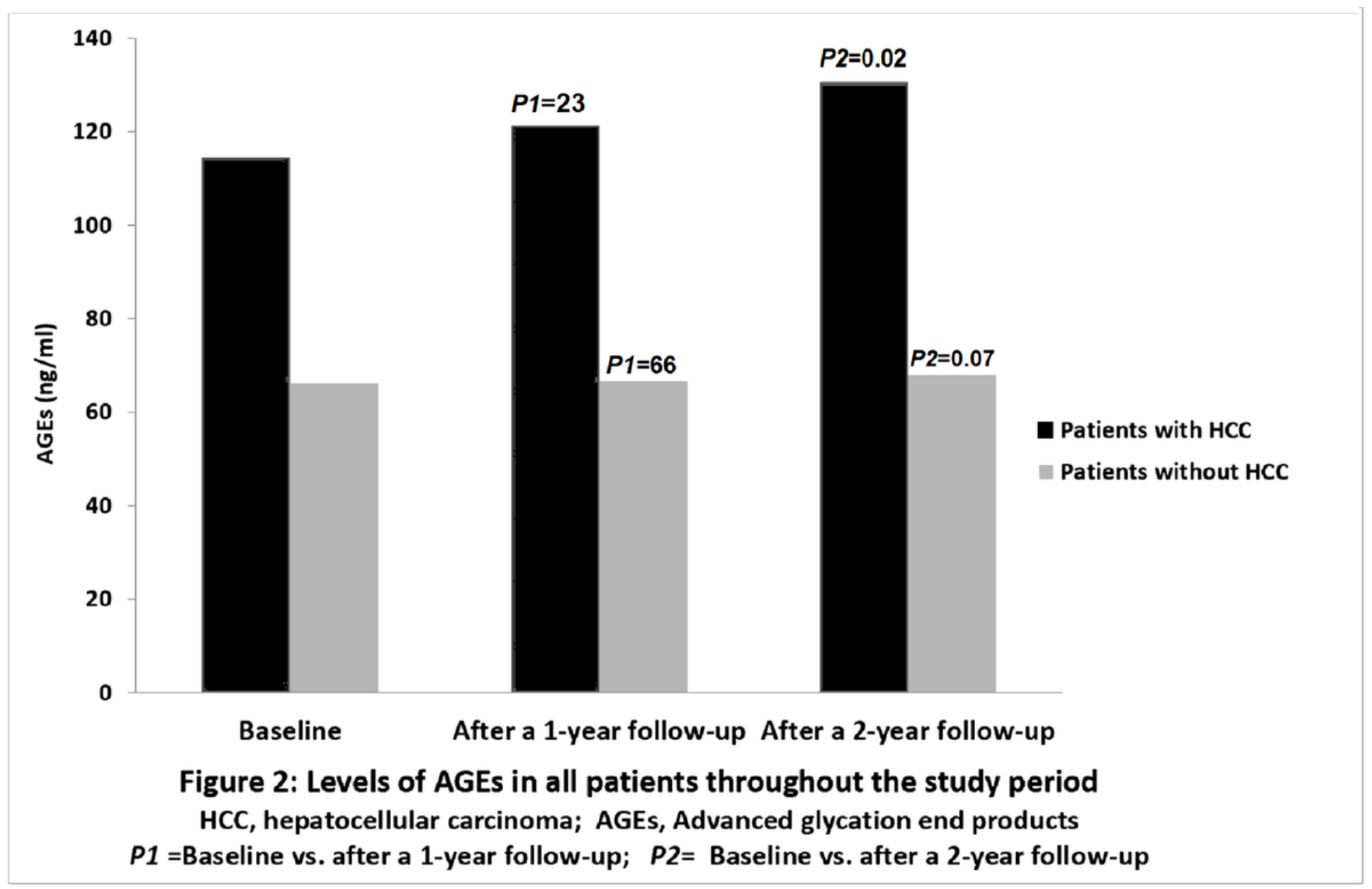

Figure 2

Levels of AGEs in all patients throughout the study period. 


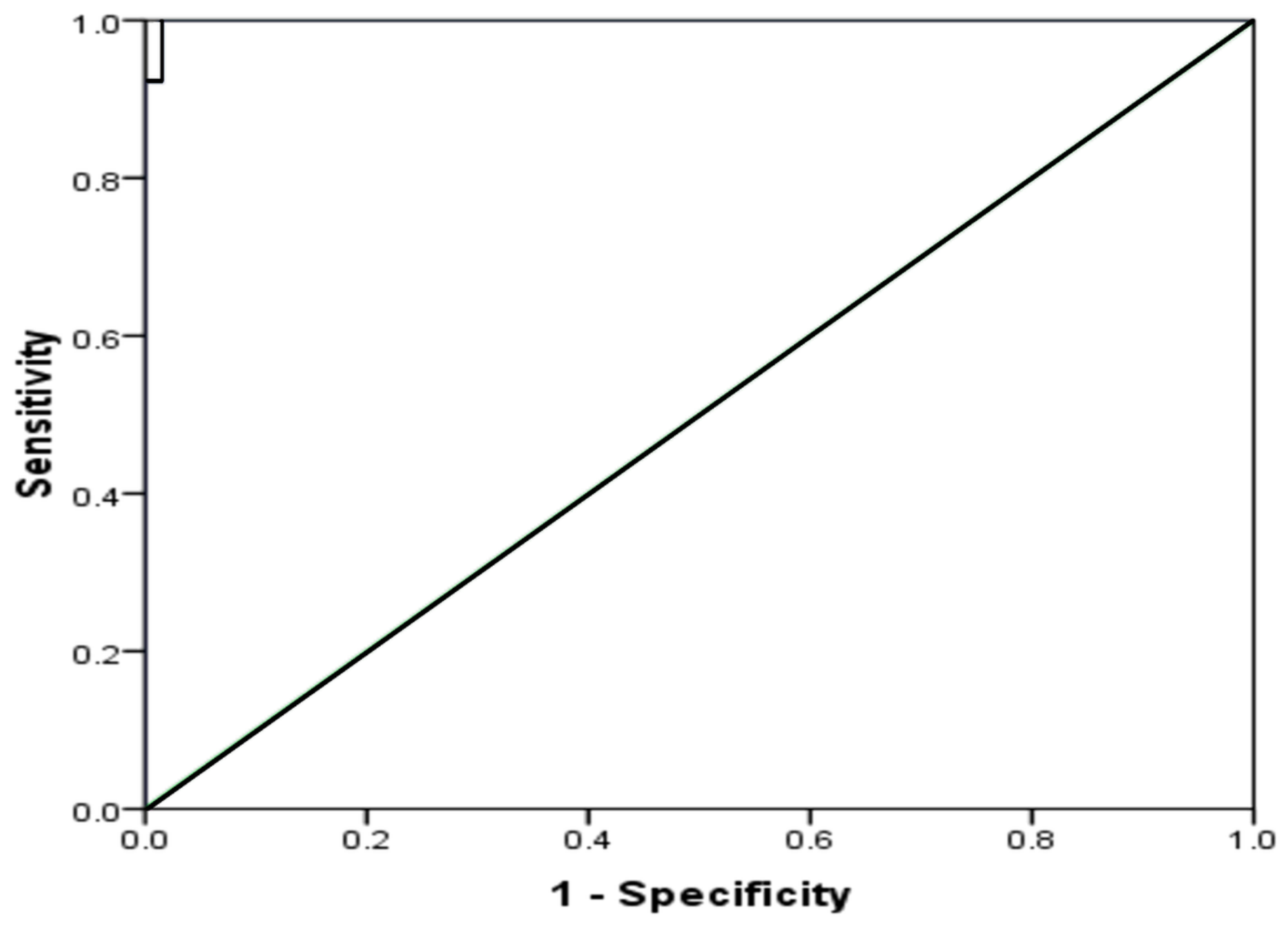

Figure 3

The receiver operating characteristic curve of AGEs in predicting HCC in patients with cirrhosis. 